\title{
A newly identified immunodominant membrane protein (pMB67) involved in Mycoplasma bovis surface antigenic variation
}

\author{
Annett Behrens, ${ }^{1}+$ François Poumarat, ${ }^{2}$ Dominique Le Grand, ${ }^{3}$ \\ Martin Heller and Renate Rosengarten ${ }^{1,5} \neq$
}

Author for correspondence: Renate Rosengarten. Tel: +43125077 2101. Fax: +431250772190.

1 Institut für Mikrobiologie und Tierseuchen,

Tierärztliche Hochschule Hannover, Bischofsholer

Damm 15, 30173

Hannover, Germany

2 CNEVA-Lyon, Laboratoire de Pathologie Bovine, BP 7033, 69342 Lyon Cedex 07, France

${ }^{3}$ Ecole Nationale Vétérinaire de Lyon, Pathologie du Bétail, BP 83, 69280 Marcy-L'Etoile, France

4 Institut für Veterinărmedizin und gesundheitlichen Verbraucherschutz, Postfach, 07722 Jena, Germany

${ }^{5}$ Institut für Bakteriologie und Tierhygiene, Veterinärmedizinische Universität Wien, JosefBaumann-Gasse 1, 1210 Wien, Austria

\begin{abstract}
Mycoplasma bovis is a bovine pathogen able to cause systemic disease. It possesses a series of prominent, structurally related yet clearly distinguishable membrane lipoproteins on the cell surface. These variable surface proteins (Vsps) undergo highly dynamic and spontaneous changes in size and expression and are key immunogenic components. They may play a critical role as mediators of adherence to host cells and in escaping immune destruction. In this report, we define a novel, Vsp-unrelated membrane protein also associated with $\boldsymbol{M}$. bovis surface antigenic variation. This protein has an apparent molecular mass of $67000 \mathrm{Da}$ in the type strain PG45 and was designated pMB67. Immunological and biochemical characterization of pMB67 demonstrated that it: (i) contains a specific epitope, (ii) is not modified by lipid but does contain cysteine, (iii) does not contain a Vsp-like repetitive periodic protein structure, (iv) is a predominant antigen recognized during $M$. bovis infections, ( $v$ ) undergoes a high rate of phase variation in vitro and (vi) is sizevariable. These results showed that $M$. bovis employs two types of specialized membrane proteins for surface diversification. The pMB67 protein may be useful in diagnostic assays and as a vaccine component.
\end{abstract}

Keywords: Mycoplasma bovis, variable membrane proteins, immunodominant antigens, surface antigenic variation, phase variation

\section{INTRODUCTION}

Mycoplasma bovis is one of the most important pathogenic bovine mycoplasmas. In contrast to many other species, which colonize the mucosal surfaces and establish localized chronic infections, this organism has the potential to cross mucosal barriers (Howard et al., 1987) and cause systemic infections after entering the bloodstream. This ability to disseminate systemically may account for the isolation of $M$. bovis from multiple body sites (Ross,

†Present address: Institut für Molekularbiologie und Medizinische Chemie, Universitătsklinikum, Leipziger Straße 44, 39120 Magdeburg. Germany.

$\ddagger$ Present address: Institut für Bakteriologie und Tierhygiene, Veterinärmedizinische Universităt Wien, Josef-Baumann-Gasse 1, 1210 Wien, Austria.

Abbreviations: $p A b$, polyclonal antibody; TX-114, Triton X-114; Vsp(s), variable surface protein(s) (lipoprotein family).
1985 ) and its association with a variety of clinical manifestations, such as mastitis (Brown et al., 1990), arthritis (Hjerpe \& Knight, 1972), pneumonia (Gourlay et al., 1989), subcutaneous abscesses (Kinde et al., 1993), meningitis (Stipkovits et al., 1993) and infertility (Ruhnke, 1994). Despite attempts at eradication, M. bovis infections are prevalent worldwide with a particularly high incidence in Europe and North America (Pfützner, 1990 ; ter Laak et al., 1992; Nicolet, 1994) and present a continuing significant problem that is economically damaging to the dairy and meat industry. Failure to prevent and control $M$. bovis-induced diseases is due to the ineffectiveness of antibiotic therapy and, in particular, the lack of vaccines for economically feasible prophylactic immunization and of specific and sensitive commercially available diagnostic tools (Pfützner, 1990; ter Laak et al., 1992).

An understanding of the pathogenesis of systemic disease caused by $M$. bovis is necessary for rational vaccine design. 
Previous work has focussed on the identification and structural analysis of $M$. bovis surface antigens which are prominent targets of the bovine immune response and may influence key host interactions. This has resulted in the identification of a family of multiple membrane surface lipoproteins with three defined members (VspA, VspB and $\mathrm{VspC}$ ) which (i) contain cross-reactive epitopes, i.e. can be recognized by cross-reactive monoclonal and polyclonal antibodies ( $\mathrm{mAbs}$ and pAbs, respectively) (Rosengarten et al., 1994; Behrens et al., 1994); (ii) undergo a high rate of size and phase variation in vitro (Rosengarten et al., 1994; Behrens et al., 1994); (iii) are encoded by a family of vsp genes (I. Lysnyansky, R. Rosengarten \& D. Yogev, unpublished results); (iv) are expressed by invasive $M$. bovis isolates, for instance, those from joints and urine (Rosengarten et al., 1994); (v) are among the predominant antigens recognized during infection and disease (Rosengarten et al., 1994); (vi) may be involved in $M$. bovis adhesion to host cells (Sachse et al., 1996); and (vii) may have diagnostic and immunoprophylactic value despite their variation (Rosengarten $e t$ al., 1994; Behrens et al., 1994).

Recent preliminary observations have suggested that $M$. bovis may utilize more than one antigenic variation system for surface diversification (Poumarat et al., 1994); however, the biochemical nature and cellular location of these components have not been extensively defined. The present study confirms these observations and demonstrates that an abundant membrane surface protein that is antigenically and structurally unrelated to the Vsp family contributes to surface variation of $M$. bovis. This protein may act as a major immunological target during infection and may prove useful in serodiagnosis, epidemiological studies and vaccine development.

\section{METiODS}

Mycoplasmas and culture conditions. $M$. bovis strains PG45 (type strain), D857, D1499, D1115 and D1511 have been previously described (Rosengarten et al., 1994); strains D857, D1499, D1115 and D1511 are field isolates which have not been filter-cloned (Rosengarten et al., 1994). All strains were cultured in the medium of Rosengarten et al. (1994). Subclones of type strain PG45 were obtained and screened for expression of surface antigens as described elsewhere (Rosengarten et al., 1994; Behrens et al., 1994).

Antibodies. Two mAbs directed toward distinct $M$. bovis membrane surface proteins were used in this study: $\mathrm{mAb} 1 \mathrm{E} 5$ is an immunoglobulin $(\operatorname{Ig}) \mathbf{M}(\kappa)$ isotype and recognizes a surface epitope on at least three members of the variable integral membrane surface lipoprotein (Vsp) family of $M$. bovis (Rosengarten et al., 1994; Behrens et al., 1994); mAb $\mathrm{I}_{2}$ (Poumarat et al., 1994) was kindly provided by Vétoquinol Biotechnologie and found here to be $\operatorname{an} \operatorname{IgG1}(\kappa)$ isotype. Other antibodies used were $\mathrm{pAb}$ anti-D490, a rabbit hyperimmune serum prepared against $M$, bovis strain $\mathrm{D} 490$, and serum sample D74, from a cow with naturally induced $M$. bovis arthritis (Rosengarten et al., 1994). For immunostaining of blots, antibodies were diluted 1:50 (bovine serum D74), 1:100 (mAb $1 \mathrm{E} 5)$ or $1: 1000\left(\mathrm{mAb} \mathrm{I}_{2} ; \mathrm{pAb}\right.$ anti-D490) in phosphate-buffered saline (PBS; $2.7 \mathrm{mM} \mathrm{KCl}, 1.5 \mathrm{mM} \mathrm{KH} \mathrm{PO}_{4}, 137 \mathrm{mM} \mathrm{NaCl}$, $8.0 \mathrm{mM} \mathrm{NaH} \mathrm{PO}_{4}, \mathrm{pH} 7.2$ ) for colony blots or PBS containing $0 \cdot 1 \%(\mathrm{v} / \mathrm{v})$ Tween 20 (PBS-T) for Western blots.

Mycoplasma antigen analysis. The procedures for Triton $\mathrm{X}$ 114 (TX-114; Boehringer Mannheim) phase fractionation, metabolic labelling with $\left[{ }^{35} \mathrm{~S}\right]$ cysteine and $\left[{ }^{3} \mathrm{H}\right]$ palmitate, SDSPAGE, fluorography and Western blotting of mycoplasma proteins were as previously described (Rosengarten $e t$ al., 1994 ; Behrens et al., 1994). For SDS-PAGE, samples were treated at $100{ }^{\circ} \mathrm{C}$ for $5 \mathrm{~min}$ under reducing conditions and loaded onto $9 \%(\mathrm{w} / \mathrm{v})$ polyacrylamide gels containing $3 \%(\mathrm{w} / \mathrm{v})$ urea. Gels containing radiolabelled proteins were fluorographed for $7-10$ weeks at $-80^{\circ} \mathrm{C}$. For Western blot analysis of unlabelied or $\left[{ }^{35} \mathrm{~S}\right]$ cysteine-labelled phase-fractionated or whole-cell proteins, blots were incubated for $1 \mathrm{~h}$ at $60^{\circ} \mathrm{C}$, blocked overnight at $4{ }^{\circ} \mathrm{C}$ with PBS containing $3 \%(\mathrm{w} / \mathrm{v})$ bovine serum albumin, washed three times in PBS-T and then incubated overnight at $4^{\circ} \mathrm{C}$ with the primary antibodies. After washing with PBS-T, blots were incubated for at least $2 \mathrm{~h}$ at room temperature in peroxidaseconjugated secondary antibodies (goat; Nordic) against mouse IgM, mouse IgG or rabbit immunoglobulins, each diluted 1:1000 in PBS-T. After repeated washing in PBS, blots were developed using 4-chloro-1-naphthol. Blots containing $\left[{ }^{35} \mathrm{~S}\right]$ cysteine-labelled proteins were autoradiographed for 10 weeks by direct exposure to films at $-80^{\circ} \mathrm{C}$. To determine the surface location and orientation of pMB67, intact organisms from fresh broth cultures were treated with various amounts of trypsin or carboxypeptidase $\mathrm{Y}$ (which has a strict requirement for a free C-terminal residue) as previously described (Behrens $e t$ $a l ., 1994)$ and the digestion products analysed in Western blots as described above.

Colony immunoblotting. The variable expression of pMB67 and Vsps within $M$. bovis clonal populations was detected in colony immunoblots which were prepared as previously described (Rosengarten et al., 1994; Behrens et al., 1994). To distinguish among clonal variants expressing pMB67 or Vsps (VspA, VspB and $\mathrm{VspC}$ in any combination) only, and those coexpressing pMB67 and Vsps, colony blots were consecutively immunostained with $\mathrm{mAbs} \mathrm{I}_{2}$ and $1 \mathrm{E} 5 \mathrm{using}$ the chromogenic substrates 4-chloro-1-naphthol, which gives a blue colour reaction (for detection of pMB67), and a-dianisidine, which gives a brown colour reaction (for detection of Vsps). Colonies co-expressing pMB67 and Vsps showed a mixed colour (brownblue).

\section{RESULTS}

\section{Identification of a prominent $67 \mathrm{kDa}$ antigen (pMB67) in $M$. bovis type strain PG45 that has different-sized counterparts in other $M$. bovis strains}

Identical blots of whole-cell proteins from broth-grown $M$. bovis strain PG45 and four additional strains were separately immunostained with the Vsp-specific mAb $1 \mathrm{E} 5$ (Fig. 1a) and $\mathrm{mAb} \mathrm{I}_{2}$ (Fig. 1b). The results obtained with $\mathrm{mAb} I_{2}$ identified a set of antigens exhibiting size polymorphism among the five strains analysed, with up to three differently sized multiple antigens within a single strain (Fig. 1b, lanes 1-3), as recently reported (Poumarat et al., 1994). Close comparison of the two immunoblots prepared using $\mathrm{mAb} 1 \mathrm{E} 5$ and $\mathrm{mAb}_{2}$ revealed striking differences in the migration patterns of the antigens 

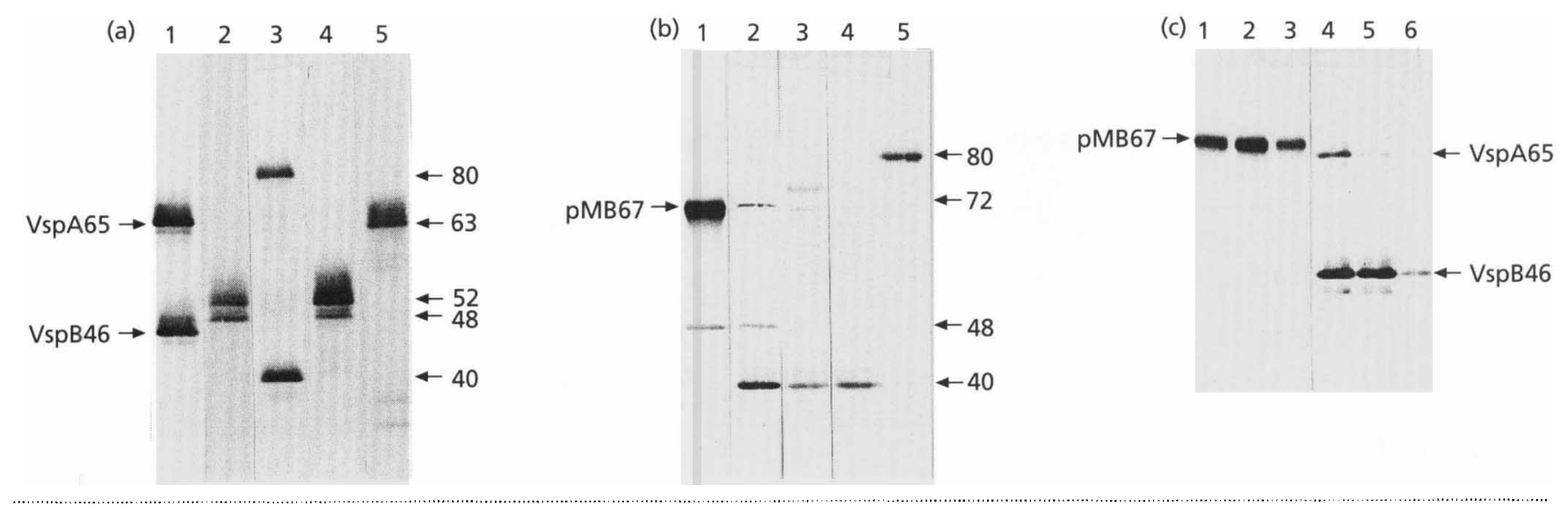

Fig. 1. Identification of a $67 \mathrm{kDa}$ strain-variant $M$. bovis antigen, pMB67, that is not recognized by $V$ sp-specific mAb $1 E 5$. $(a, b)$ Western immunoblot analysis of whole-organism proteins from $M$. bovis type strain PG45 (lanes 1) and strains D857 (lanes 2), D1499 (lanes 3), D1115 (lanes 4) and D1511 (lanes 5) with mAb $1 E 5$ (a) or I (b). Each lane contains proteins from equal quantities $(20 \mu \mathrm{l})$ of mid-exponential-phase cultures. The positions of VspA65 and VspB46 (a) and pMB67 (b) as expressed by the type strain are indicated on the left. The positions and relative molecular masses (in kDa) of as yet undefined Vsps (a) and pMB67-related size-variant antigens (b) expressed by the other four strains are indicated on the right. (c) Equivalent amounts of total cell protein [13 (lanes 1-3) and 6 (lanes 4-6) $\mu 1$ culture per lane] from three clonal variants of strain PG45 (clone 26, lanes 1 and 4 ; clone 27, lanes 2 and 5; clone 28, lanes 3 and 6) were run in two sets of adjacent lanes and the resulting blot was divided and immunostained with mAb $\left.\right|_{2}$ (lanes 1-3) and mAb 1E5 (lanes 4-6). The positions of pMB67, VspA65 and VspB46 are indicated.

recognized; indeed, none of the five strain- and sizevariant antigens recognized by $\mathrm{mAb} \mathrm{I}_{2}$ (Fig. $1 \mathrm{~b}$ ) could be identified as $\mathrm{mAb} 1 \mathrm{E} 5$-binding Vsp (Fig. 1a). Although a $48 \mathrm{kDa}$ antigen of $M$. bovis D857 (Fig. 1b, lane 2) and a $40 \mathrm{kDa}$ antigen of $M$. bovis D1499 (Fig. 1b, lane 3) recognized by $\mathrm{mAb} \mathrm{I}_{2}$ co-migrated with a Vsp product (Fig. 1a, lanes 2 and 3, respectively) in these strains, the corresponding bands were not identical, since the distribution of these two mAb- $\mathrm{I}_{2}$-defined antigens among the five strains analysed (Fig. 1b) did not correspond to the strain distribution of the two similar-sized Vsps (Fig. 1a).

The most prominent antigen reacting with $\mathrm{mAb} \mathrm{I}_{2}$ was identified in the type strain PG45 (Fig. 1b, lane 1). This antigen was confirmed to be a protein by its susceptibility to trypsin degradation as well as its labelling properties (see below) and was designated by its apparent molecular mass in $\mathrm{kDa}$ as pMB67. To further confirm that this antigen was a distinct product and not a size variant form of $V \operatorname{spA}$ (compare Fig. $1 \mathrm{a}$ and $b$, lanes 1), equivalent amounts of total protein from three clonal variants of type strain PG45 were subjected in replicate to SDS-PAGE, and subsequent blots (Fig. 1c) were immunostained with $\mathrm{mAb} \mathrm{I}_{2}$ (lanes 1-3), $\mathrm{mAb} 1 \mathrm{E} 5$ (lanes 4-6) or $\mathrm{pAb}$ antiD490 (data not shown). The resolution provided by these immunoblots allowed unambigous identification of pMB67 as a discrete translational product with a reaction profile (binding of $\mathrm{mAb} \mathrm{I}_{2}$ only) distinct from that of VspA (binding of $\mathrm{mAb} 1 \mathrm{E} 5$ and $\mathrm{pAb}$ anti-D490; see also Rosengarten et al., 1994). Also apparent was the noncoordinate expression of pMB67, VspA and VspB, since all three clonal variants displayed different levels of expression of $\mathrm{Vsp} A$ or $\mathrm{VspB}$, while $\mathrm{pMB} 67$ was expressed in similar quantities.

\section{pMB67 is a surface-exposed, membrane-associated nonlipoprotein with a free C-terminus}

The localization and topology of pMB67 on the external surface of $M$. bovis was examined, using $\mathrm{mAb}_{2}$ to monitor its susceptibility to trypsin- and carboxypeptidase-Y-digestion in intact mycoplasma cells prepared from mid-exponential-phase cultures. Western blots of these preparations showed a gradual reduction of staining with increasing enzyme concentration (Fig. 2a and b), without generation of smaller epitope-bearing degradation products. In contrast, digestion of $\mathrm{VspA}, \mathrm{VspB}$ and $\mathrm{VspC}$ with carboxypeptidase $\mathrm{Y}$ gave a series of products of varying size, which could be immunostained with $\mathrm{mAb} 1 \mathrm{E} 5$, and following digestion with trypsin the smallest immunoreactive fragments ranged from 41 to $45 \mathrm{kDa}$ (Behrens et al, 1994). These results established that (i) pMB67 is located on the organism's surface, (ii) its $\mathrm{C}$-terminus has a free carboxyl residue that is accessible on the surface, and (iii) its enzyme digestion profiles are clearly distinguishable from those of Vsps.

Although Poumarat et al. (1994) indicated that the strainvariant antigenic components recognized by $\mathrm{mAb}_{2}$ are associated with the membrane, the biochemical nature and location of these antigens have not becn extensively defined. Using procedures previously described (Rosengarten et al., 1994; Behrens et al., 1994), we were able to provisionally classify pMB67 as an integral 


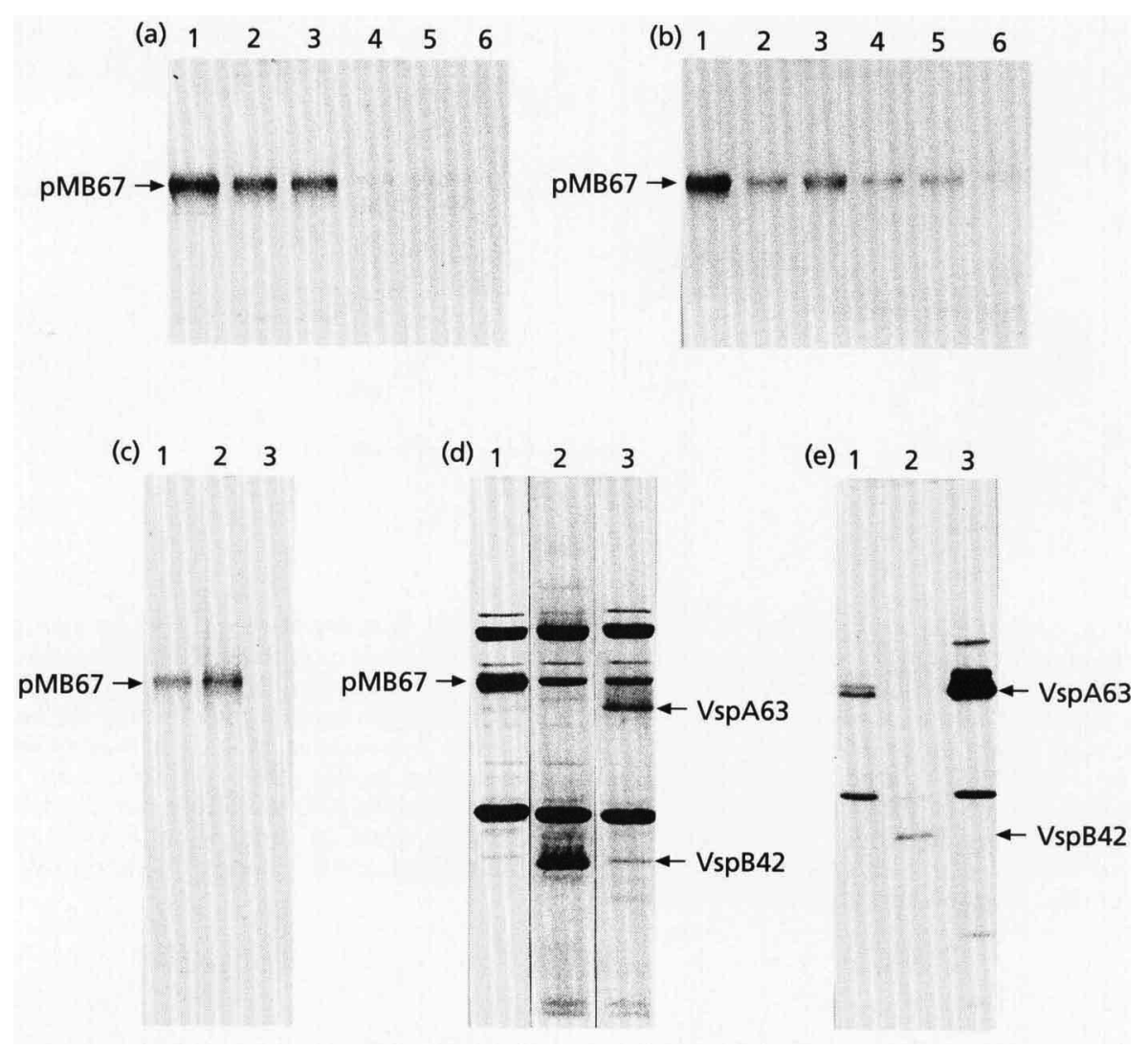

Fig. 2. Biochemical characteristics of pMB67. (a,b) Susceptibility of pMB67 to trypsin and carboxypeptidase $Y$ treatment of intact cells. Fresh broth-grown cells ( $25 \mu \mathrm{l}$ culture per sample) of a clonal variant of $M$. bovis PG45 incubated with increasing concentrations of trypsin (a) or carboxypeptidase $Y$ (b) were subjected to SDS-PAGE and the subsequent Western blots immunostained with mAb $\mathrm{I}_{2}$. Lanes 1 represent organisms incubated in enzyme buffer, lanes 2-6 represent organisms treated, respectively, with $5,10,20,50$ or $100 \mu \mathrm{g}$ trypsin $\mathrm{ml}^{-1}$ (a), or with 40, 100, 150, $200 \mathrm{or} 400 \mu \mathrm{g}$ carboxypeptidase $Y \mathrm{ml}^{-1}$ (b). Restaining of the blots with pAb anti-D490 showed that the cytoplasmic protein p41 (Rosengarten et al., 1994) was not degraded, so confirming that cells remained intact during digestion (data not shown). (c) TX-114 phase partitioning characteristics of pMB67. Broth-cultured organisms of a clonal variant of $M$. bovis PG45 were phase-fractionated with TX-114, and whole-organism proteins (lane 1), TX-114 phase proteins (lane 2) or aqueous phase proteins (lane 3) were separated by SDS-PAGE and immunoblotted with mAb $I_{2}$. (d, e) Metabolic labelling characteristics of pMB67. TX-114 phase proteins metabolically labelled with $\left[{ }^{35}\right.$ S cysteine (d) or $\left[{ }^{3} \mathrm{H}\right]$ palmitate (e) from selected clonal isolates of $M$. bovis PG45 expressing pMB67 (lanes 1), VspB42 (lanes 2) or VspA63 (lanes 3) were separated by SDS-PAGE and analysed by fluorography. Identical populations are represented in the corresponding lanes. Samples in panel (c) contained whole-organism (lane 1) or phase-fractionated proteins (lanes 2 and 3) from 10 (lane 1), 25 (lane 3) or 180 (lane 2) $\mu \mathrm{l}$ mid-exponential-phase cultures. Each lane in panels (d) and (e) represents TX-114 phase proteins from $1800 \mu \mathrm{l}$ mid-exponential-phase cultures. pMB67, VspA63 and VspB42 visualized by immunostaining and/or radiolabelling are indicated. The autoradiographic signal of the VspB42 band in panel (e) (lane 2) is weak because of the limited quantity of total protein present.

membrane protein with characteristics of a nonlipoprotein. Firstly, the clear separation of $\mathrm{pMB} 67$ as an amphiphilic product into the detergent phase during ' $\mathrm{TX}$ 114 phase fractionation of whole organisms allowed its identification as a putative integral membrane protein (Fig. 2c). And secondly, comparison of TX-114 phase proteins from $\left[{ }^{35} \mathrm{~S}\right]$ cysteine- or $\left[{ }^{3} \mathrm{H}\right]$ palmitate-labelled organisms, visualized by fluorography, revealed that pMB67 contained cysteine (Fig. 2d, lane 1) but not fatty acid (Fig. 2e, lane 1). In contrast, a $63 \mathrm{kDa}$ size variant of VspA (Fig. 2d and e, lanes 3) and a $42 \mathrm{kDa}$ size variant of VspB (Fig. 2d and e, lanes 2) which served as control markers, were labelled with both compounds (Behrens et al., 1994). This was tigorously confirmed by immunostaining Western blots of radiolabelled TX-114 phase proteins, followed by autoradiography to precisely align immunostained bands with their radiolabelled counterparts (data not shown).

\section{pMB67 undergoes high-frequency in vitro phase variation and is size-variable}

Western blot immunoscreening with pMB67-specific $\mathrm{mAb} \mathrm{I}_{2}$ of a series of colonies, which were randomly selected from a cloned subpopulation, revealed a striking heterogeneity in the relative amount of pMB67 present in 
(a) $1 \begin{array}{llllllllllllllll}2 & 2 & 3 & 4 & 5 & 6 & 7 & 8 & 9 & 10 & 11 & 12 & 13 & 14 & 15 & 16\end{array}$
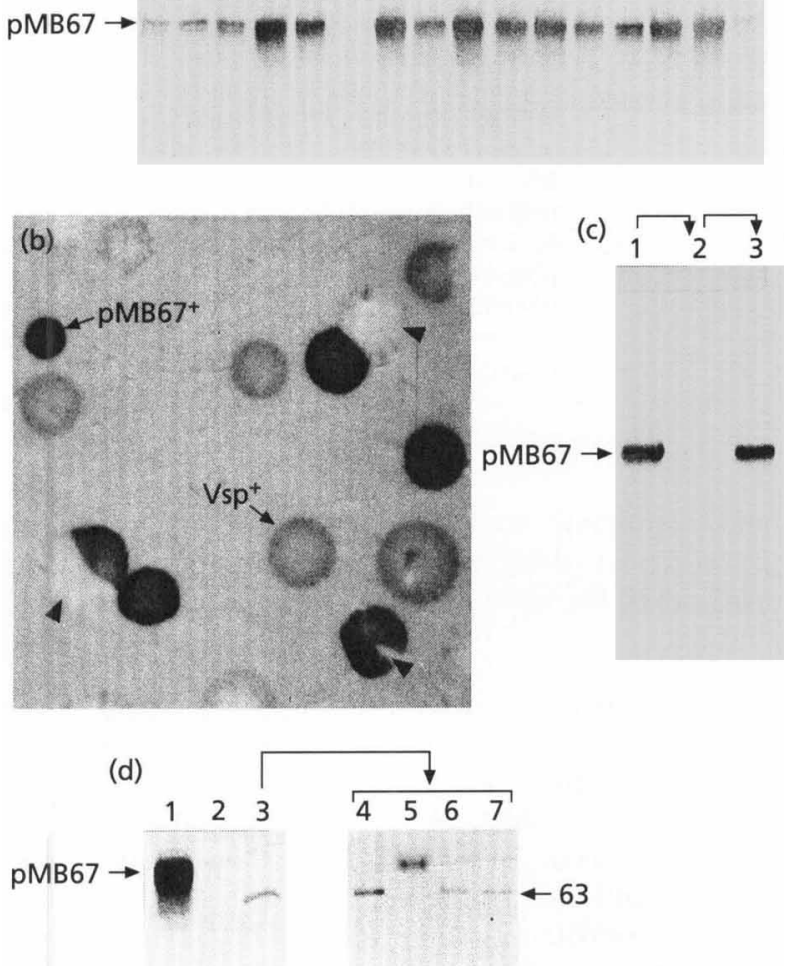

Fig. 3. Variation in expression and size of pMB67. (a) Different expression levels of pMB67 among broth-cultured randomlyselected isolates of a clonal subpopulation of $M$. bovis PG45 (clone 26, see Fig. 1c, lanes 1 and 4). Whole-organism proteins from $25 \mu \mathrm{l}$ of mid-exponential-phase cultures were separated by SDS-PAGE and immunoblotted with $M A b I_{2}$. The blot was restained with $\mathrm{pAb}$ anti-D490 recognizing invariant protein $\mathrm{p} 41$ (Rosengarten et al., 1994), which served as a control to ensure that similar amounts of organisms were loaded per sample (data not shown). (b) Colony immunoblot of a clonal population of $M$. bovis PG45 demonstrating phase variation in expression of pMB67. The blot was immunostained with Vspspecific mAb $1 E 5$ using $o$-dianisidine as chromogenic substrate giving a light brown colour reaction and restained with $\mathrm{mAb} \mathrm{I}_{2}$ to pMB67 using 4-chloro-1-naphthol as chromogenic substrate giving a dark blue colour reaction. A representative portion of the blot is shown. One colony variant displaying the pMB67 $7^{+} \mathrm{vsp}$ phenotype and one colony variant displaying the pMB67- $\mathrm{Vsp}^{+}$phenotype are indicated. Two colonies and one colony sector showing the $\mathrm{pMB67^{- }} \mathrm{Vsp}^{-}$phenotype (negative reaction) are indicated by arrowheads. (c) Western blot analysis of whole-organism proteins from a clonal lineage of $M$. bovis PG45 with $\mathrm{mAb}_{2}$ showing phase variation in expression of pMB67 ('phase on' $\rightarrow$ 'phase off' $\rightarrow$ 'phase on') corresponding to the selected colony phenotype. Phase transitions are indicated by arrows above lanes. Each lane contains proteins from $20 \mu \mathrm{l}$ mid-exponential-phase cultures. (d) Western blot analysis of total proteins from three randomly selected clonal subpopulations of $M$. bovis PG45 clone 26 (lanes 1-3) with $\mathrm{mAb}$ $\mathrm{I}_{2}$, one of which (lane 3) expressed a $63 \mathrm{kDa}$ size variant of pMB67. Progeny populations (lanes 4-7) of this clonal variant showed stable expression of the $63 \mathrm{kDa}$ size variant (lanes 4, 6 and 7) or reversion to the original $67 \mathrm{kDa}$ form of pMB67 (lane 5). The position and size of the smaller pMB67 is indicated by the arrow on the right. Each lane contains proteins from $25 \mu \mathrm{l}$ mid-exponential-phase cultures. The bands of pMB67 in lane 5 and of the smaller $63 \mathrm{kDa}$ variant are less prominent because of the limited quantity of total protein present in these lanes. the broth-cultured populations analysed (Fig. 3a). For example, while the clonal variants represented in lanes 4 , 5,7 and 9 showed a strong relative staining intensity of this protein, those represented in lanes 1-3 showed a much weaker staining of the corresponding band, and in one clonal variant (lane 6), pMB67 was not detectable. pMB67 expression variants were plated and analysed by colony immunoblotting with $\mathrm{mAb} \mathrm{I}_{2}$ enabling identification of both pMB $67^{+}$and pMB67 $7^{-}$colony variants within the various populations analysed. One example of this colony immunoblot analysis demonstrating a mixed population of $\mathrm{pMB} 67^{+}$and $\mathrm{pMB} 67^{-}$variants is illustrated in Fig. 3(b). Restaining of these colony blots with Vspspecific $\mathrm{mAb} 1 \mathrm{E} 5$ allowed the identification of four different $\mathrm{mAb}$-binding phenotypes (three of which are shown in Fig. 3b), and further confirmed (see above) that the expression of pMB67 is not coordinately linked with the expression of VspA, VspB or VspC. The following observations unequivocally established that $\mathrm{pMB} 67$ was indeed subject to high-frequency $\left(10^{-3}\right.$ to $10^{-4}$ per generation) reversible phase switching. Firstly, further propagation and replating of colonies scored as $\mathrm{pMB} 67^{+}$ or pMB $67^{-}$revealed that a small fraction $(0.7-8.0 \%)$ of progeny colonies always showed the alternate (negative or positive) phenotype (data not shown). Secondly, these phase variants gave tise in turn to revertants expressing the original phenotype (data not shown). Thirdly, colonies frequently displayed a sectored pattern of immunostaining, indicating switching between the $\mathrm{pMB} 67^{+}$and pMB67 $7^{-}$phenotype during colonial growth (Fig. 3b). And finally, Western immunoblot analysis of clonal lineages selected by colony immunoblots and representing successive generations clearly showed oscillating expression of pMB67, for example (as shown in Fig. 3c), from 'phase on' (lane 1) to "phase off' (lane 2) and again to 'phase on' (lane 3).

Another feature of pMB67, also characteristic of the Vsps (Rosengarten et al., 1994; Behrens $e t$ al., 1994), was size variation. One example of this size variability is illustrated in Fig. 3(d), in which a $63 \mathrm{kDa}$ size variant of pMB67 (lane 3 ) is shown to spontaneously revert to the original size form of $67 \mathrm{kDa}$ (lane 5). However, in contrast to Vsp size variants (Behrens et al., 1994), size variants of pMB67 were detected at a very low frequency. In addition, simultaneous appearance of a number of size variants in ladder-like patterns, as reported for the Vsp system (Behrens et al., 1994), was never observed, even in heavily loaded samples (see Fig. 3d, lane 1).

\section{pMB67 is a major immunogen of $M$. bovis recognized during infection and disease}

The finding that pMB67 was a major surface antigen of $M$. bovis raised the possibility that it may be an important immunogenic component during infection and disease, as recently demonstrated for the Vsps (Rosengarten et al., 1994). To determine whether this was the case, serum from a cow with naturally induced $M$. bovis arthritis (Rosengarten et al., 1994) was used (Fig. 4c) in conjunction 


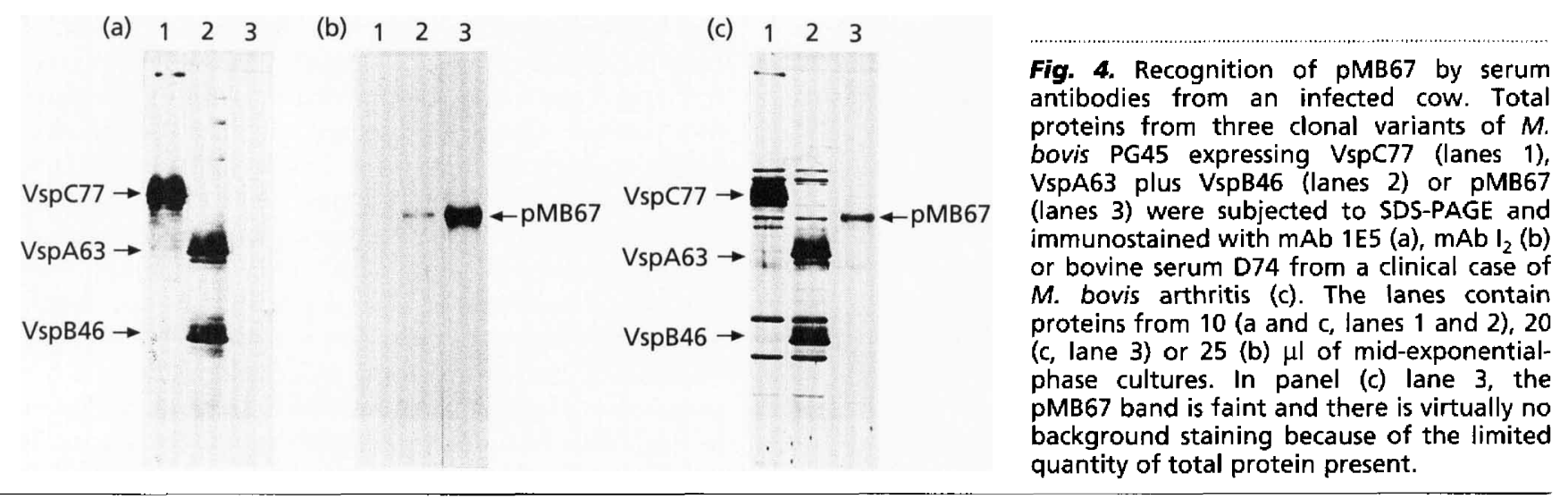

with $\mathrm{mAb} 1 \mathrm{E} 5$ (Fig. 4a) and $\mathrm{mAb} \mathrm{I}_{2}$ (Fig. 4b) to probe Western blots of whole-cell proteins from three clonal variants expressing a set of Vsps (lanes 1 and 2) and pMB67 (lanes 3). Comparison of the three immunoblots which were prepared from the same gel showed precise alignment of the individual $\mathrm{mAb}$-defined antigens, i.e. VspA, VspB, VspC and pMB67 (Fig. 4a and b), with the most prominent bands immunostained by the bovine serum antibodies (Fig. 4c). Western immunoblot analysis of other serum samples from $M$. bovis-infected cattle confirmed these data (not shown). These results demonstrated that pMB67 is among the major $M$. bovis components that induce antibody during natural infection and disease.

\section{DISCUSSION}

The identification of $M$. bovis surface structures potentially involved in immune evasion, colonization and invasion is of fundamental importance for understanding the pathogenesis of $M$. bovis systemic infections and for developing effective immunological intervention strategies. In previous studies such surface components, which may play an important role in mycoplasma-host interactions (Sachse et al., 1996) have been identified as membraneassociated surface lipoproteins (Vsps) which undergo high-frequency phase and size variation (Rosengarten $t$ al., 1994; Behrens et al., 1994). The present study has defined a new major $M$. bovis antigen, designated pMB67, that has no antigenic or structural similarity to the Vsps, but is endowed with all the attributes characteristic of a functionally important variable antigenic component. Firstly, it is localized on the organism's surface, where it displays a specific mAb-defined epitope. Secondly, it is a prominent integral membrane protein that is, unlike the Vsps, not lipid-modified and apparently does not contain multiple repeating subunits. Thirdly, it undergoes highfrequency phase variation in expression and is sizevariable within clonal populations. Moreover, since it can be independently expressed in combination with Vsps, it greatly increases the capacity of this organism to generate and maintain a structurally, antigenically and functionally versatile surface. Finally, it is a dominant target of the bovine immune response during natural infection. 'Thus, like the Vsps, pMB67 may enable $M$. bovis to exist as a mixed population with differing properties that are of importance at different stages of infection and may contribute to the ability of this mycoplasma to resist host defences.

The results presented here were highly reproducible and not altered by the passage number of cultures (data not shown). Together with results previously reported (Behrens et al., 1994), they establish that the variable surface antigens of $M$. bovis fall into two distinct classes of integral membrane proteins, namely (i) classical prokaryotic lipoproteins, which are anchored in the membrane by fatty acid moieties covalently linked to an $\mathrm{N}$ terminal cysteine residue in the processed mature product (Wu, 1987; Wise, 1993; Cleavinger et al., 1994), and (ii) nonlipoproteins, which are either membrane-anchored through hydrophobic transmembrane domains in the primary amino acid sequence, as recently shown for the adhesin-like protein PvpA of Mycoplasma gallisepticum (Yogev et al., 1994; D. Yogev, D. Menaker \& R. Rosengarten, unpublished results), or by other as yet unknown mechanisms, possibly including attachment to lipoprotein by a disulfide bond. While lipoproteins and their genes have now been widely established in mycoplasma surface antigenic variation systems (Rosengarten \& Wise, 1990; Yogev et al., 1991; Markham et al., 1993; Wise et al., 1993; Theiss et al., 1993; Behrens et al., 1994; Zheng et al., 1995; Bhugra et al., 1995; Simmons et al., 1996), there are only a few reports defining variable membrane proteins that are not lipid-modified. The only known examples are the $\mathrm{P} 30$ adhesin of $M$. pneumoniae (Dallo et al., 1990), the adhesin-like protein PvpA of $M$. gallisepticum (Yogev et al., 1994; D. Yogev, D. Menaker \& R. Rosengarten, unpublished results), and several distinct variable surface antigens of Mycoplasma artbritidis (Droesse et al., 1995). Thus, the data presented here add to the list of variable mycoplasma membrane proteins which are not lipoproteins. Although protein families with structural motifs similar to the $M$, bovis Vsp lipoproteins (Behrens $e t$ al., 1994; I. Lysnyansky, R. Rosengarten \& D. Yogev, unpublished tesults) have been found in Mycoplasma byorbinis (Yogev et al., 1991), Mycoplasma pulmonis (Bhugra et al., 1995; Simmons et al., 1996) and Ureaplasma urealyticum (Zheng etal., 1995), in none of these organisms has the expression of an PMB67-analogous antigen been 
demonstrated. Thus, among these mycoplasmas, M. bovis is the first reported organism that utilizes for surface diversification two superimposed antigenic variation systems, namely a large repertoirc of multiple antigenically related but distinct lipoproteins (Vsps), as well as a single membrane protein (pMB67) which is not lipidmodified. It is also noteworthy that this protein contains cysteine, whilst with one exception (the p43 antigen of $M$. artbritidis; Droesse et al., 1995), all other previously described variable surface nonlipoproteins of mycoplasmas do not.

Proteolytic analysis of pMB67 with carboxypeptidase $\mathrm{Y}$ revealed a probable surface orientation of this antigen similar to the Vsps (Behrens et al., 1994), with the Cterminal region exposed to the microenvironment surrounding the organism. This suggests that the $\mathrm{C}$-terminal domain is most likely to encounter host defences first and to elicit a dominant antibody response. However, if these antibodies promote mycoplasma killing, only cells expressing the corresponding antigens will be killed. Thus, it is quite possible that variable expression of $V$ sps and pMB67 may enable $M$. bovis to adhere to cells and invade tissues while ensuring that only a fraction of the population is potentially susceptible to antibody-mediated host defences. However, the precise function of pMB67 and the development and importance of the host immune response to this antigen remains to be elucidated. Detailed analysis of pMB67 structure and variation at the molecular level will be necessary to fully understand its significance in the establishment of systemic infection.

The finding that pMB67 and Vsps (Rosengarten $e t$ al., 1994) are selective targets of the humoral immune response in animals infected with $M$. bovis suggests that a cocktail composed of recombinant forms of these antigens might induce an effective prophylactic response to $M$. bovis. In addition, such an antigen cocktail might enable development of a sensitive immunoassay system for specific and rapid identification of $M$. bovis-infected animals. In addition to assessing the use of pMB67 and $V$ sps as a means of monitoring $M$. bovis infections in the field, future studies should also examine whether antibodies to these antigens are protective to clarify their potential as vaccine antigens.

\section{ACKNOWLEDGEMENTS}

The authors would like to thank Vétoquinol Biotechnologie for supplying $\mathrm{mAb} \mathrm{I}_{2}$ and $\mathrm{J}$. L. Martel for many helpful discussions and his generous support.

This work was supported in part by a grant (Ro 739/2-1) from the Deutsche Forschungsgemeinschaft (R. R.) and a grant (LPBUBA-No. 93-2/2) from the Centrc National d'Etudes Vétérinaires et Alimentaires (F.P.).

\section{REFERENCES}

Behrens, A., Heller, M., Kirchhoff, H., Yogev, D. \& Rosengarten, R. (1994). A family of phase- and size-variant membrane surface lipoprotein antigens (Vsps) of Mycoplasma bovis. Infect Immun 62, 5075-5084.
Bhugra, B., Voelker, L. L., Zou, N., Yu, H. \& Dybvig, K. (1995). Mechanisms of antigenic variation in Mycoplasma pulmonis: interwoven, site-specific DNA inversions. Mol Microbiol 18, 703714.

Brown, M. B., Shearer, J. K. \& Elvinger, F. (1990). Mycoplasmal mastitis in a dairy herd. J Am Vet Med Assoc 196, 1097-1101.

Cleavinger, C. M.، Kim, M. F. \& Wise, K. S. (1994). Processing and surface presentation of the Mycoplasma byorbinis variant lipoprotein VlpC. J Bacteriol 176, 2463-2467.

Dallo, S. F., Chavoya, A. \& Baseman, J. B. (1990). Characterization of the gene for a 30 -kilodalton adhesin-related protein of $\mathrm{MyO}$ plasma pnewnoniac. Infert Immun 58, 4163-4165.

Droesse, M., Tangen, G., Gummelt, I., Kirchhoff, H., Washburn, L. R. \& Rosengarten, R. (1995). Major membrane proteins and lipoproteins as highly variable immunogenic surface components and strain-specific antigenic markers of Mycoplasma artbritidis. Mirrobiology 141, 32073219.

Gourlay, R. N., Thomas, L. H. \& Wyld, S. G. (1989). Increased severity of calf pneumonia associated with the appearance of Mycoplasma bovis in a rearing herd. Vet Rec 124, 420-422.

Hjerpe, C. A. \& Knight, H. D. (1972). Polyarthritis and synovitis associated with Mycoplasma bovimastitidis in feetlot cattle. J Am Vet Med Assoc 160, 1414-1418.

Howard, C. J., Thomas, L. H. \& Parsons, K. R. (1987). Comparative pathogenicity of Mycoplasma bovis and Mycoplasma dispar for the respiratory tract of calves. Isr J Med Sci 23, 621624 .

Kinde, H., Daft, B. M., Walker، R. L., Charlton, B. R. \& Petty, R. (1993). Mycoplasma bovis associated with decubital abscesses in Holstein calves. I l'et Diagn Invest 5, 194-197.

ter Laak, E. A., Wentink, G. H. \& Zimmer, G. M. (1992). Increased prevalence of Mycoplasma bovis in the Netherlands. Fet $Q 15$, $100-104$

Markham, P. F., Glew, M. D., Whithear, K. G. \& Walker, I. D. (1993). Molecular cloning of a member of the gene family that encodes pMGA, a hemagglutinin of Mycoplasma gallisepticum. Infect Immun 61, 903-909.

Nicolet, J. (1994). Mycoplasma bovis. Ausbreitung eines neuen pathogenen Erregers beim Rindvieh in der Schweiz? Schweiz. Arch Tierbeilkd 136, 8182.

Pfutzner, H. (1990). Epizontiology of the Mycoplasma bovis infection in cattle. Zentralb/ Bakterial Suppl 20, 394-399.

Poumarat, F., Solsona, M. \& Boldini, M. (1994). Genomic, protein and antigenic variability of Mycoplasma bovis. Vet Microbiol 40 , 305-321.

Rosengarten, R. \& Wise, K.S. (1990). Phenotypic switching in mycoplasmas: phase variation of diverse surface lipoproteins. Sizence 247, 315-318.

Rosengarten, R., Behrens, A., Stetefeld, A., Heller, M., Ahrens, M., Sachse, K., Yogev, D. \& Kirchhoff, H. (1994). Antigen heterogeneity among isolates of Mycoplasma bovis is generated by high-frequency variation of diverse membrane surface proteins. Infect Immun 62, 5066-5074.

Ross, R. F. (1985). Mycoplasmas of cattle. In Handbuch der Bakteriellen Infektionen bei Tieren, vol. 5, pp. 314-344. Edited by $\mathrm{H}$. Blobel \& T. Schliesser. Stuttgart: Gustav Fischer Verlag.

Ruhnke, H. L. (1994). Mycoplasmas associated with bovine genital tract infections. In Mycoplasmosis in Animals: Laboratory Diagnosis, Pp. 56-62. Edited by H. W. Whitford, R. F. Rosenbusch \& L. H. Lauerman. Ames, 1A: Iowa State Cniversity Press.

Sachse, K., Grajetzki, C., Rosengarten, R., Hănel, I., Heller, M. \& Pfutzner, H. (1996). Mechanisms and factors involved in Mycoplasma bovis adhesion to host cells. Zentralb/ Bakteriol (in press). 
Simmons, W. L., Zuhua, C., Glass, J. I., Simecka, J. W., Cassell, G. H. \& Watson, H. L. (1996). Sequence analysis of the chromosomal region around and within the $\mathrm{V}$-1-encoding gene of Mycoplasma pulmonis: evidence for DNA inversion as a mechanism for $\mathrm{V}-1$ variation. Infect Immun 64, 472-479.

Stipkovits, L., Rady, M. \& Glavits, R. (1993). Mycoplasmal arthritis and meningitis in calves. Acta Vet Hung 41, 73-88.

Theiss, P. M., Kim, M. F. \& Wise, K. S. (1993). Differential protein expression and surface presentation generate high-frequency antigenic variation in Mycoplasma fermentans. Infect Immun 61, 5123-5128.

Wise, K. S. (1993). Adaptive surface variation in mycoplasmas. Trends Microbiol 1, 59-63.

Wise, K. S., Kim, M. F., Theiss, P. M. \& Lo, S.-C. (1993). A family of strain variant surface lipoproteins of Mycoplasma fermentans. Infect Immun 61, 3327 3333.

Wu, H. (1987). Post-translational modification and processing of membrane proteins in bacteria. In Bacterial Outer Membranes as Model Systems, pp. 37-71. Edited by M. Inouye. New York: Wiley.

Yogev, D. Rosengarten, R., Watson-McKown, R. \& Wise, K. S. (1991). Molecular basis of Mycoplasma surface antigenic variation: a novel set of divergent genes undergo spontaneous mutation of periodic coding regions and $5^{\prime}$ regulatory sequences. EMBO J 10 , 4069-4079.

Yogev, D., Menaker, D., Strutzberg, K., Levisohn, S., Kirchhoff, H., Hinz, K.-H. \& Rosengarten, R. (1994). A surface epitope undergoing phase variation is shared by Mycoplasma gallisepticum and Mycoplasma bovis. Infect Immun 62, 4962-4968.

Zheng, X., Teng, L.-J., Watson, H. L., Glass, J. I., Blanchard, A. \& Cassell, G. H. (1995). Small repeating units within the Lireaplasma urealyticum $\mathrm{MB}$ antigen gene encode serovar specificity and are associated with antigen size variation. Infect Immun 63, 891-898.

Received 7 November 1995; revised 19 April 1996; accepted 9 May 1996. 